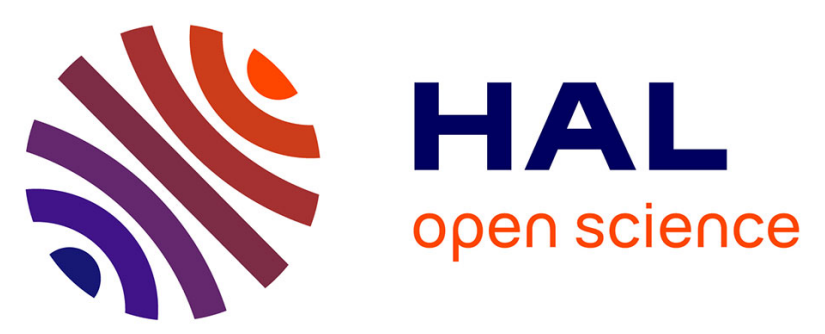

\title{
Feasibility of luminescent multilayer sol-gel thermal barrier coating manufacturing for future applications in through-thickness temperature gradient sensing
}

Etienne Copin, Thierry Sentenac, Yannick Le Maoult, Fabien Blas, Florence Ansart, Vanessa Vidal, Philippe Lours

\section{To cite this version:}

Etienne Copin, Thierry Sentenac, Yannick Le Maoult, Fabien Blas, Florence Ansart, et al.. Feasibility of luminescent multilayer sol-gel thermal barrier coating manufacturing for future applications in through-thickness temperature gradient sensing. Surface and Coatings Technology, 2014, vol. 260, pp. 90-96. 10.1016/j.surfcoat.2014.08.077 . hal-01168182

\author{
HAL Id: hal-01168182 \\ https://hal.science/hal-01168182
}

Submitted on 25 Jun 2015

HAL is a multi-disciplinary open access archive for the deposit and dissemination of scientific research documents, whether they are published or not. The documents may come from teaching and research institutions in France or abroad, or from public or private research centers.
L'archive ouverte pluridisciplinaire HAL, est destinée au dépôt et à la diffusion de documents scientifiques de niveau recherche, publiés ou non, émanant des établissements d'enseignement et de recherche français ou étrangers, des laboratoires publics ou privés. 


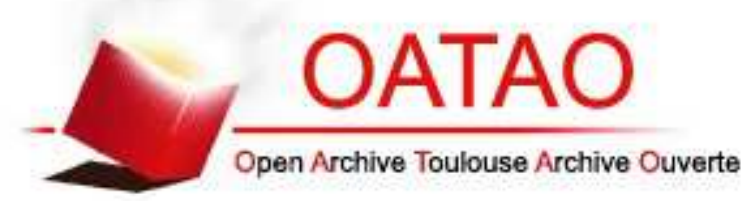

\section{Open Archive TOULOUSE Archive Ouverte (OATAO)}

OATAO is an open access repository that collects the work of Toulouse researchers and makes it freely available over the web where possible.

This is an author-deposited version published in : http://oatao.univ-toulouse.fr/ Eprints ID : 14032

To link to this article : doi: 10.1016/j.surfcoat.2014.08.077

URL : $\underline{\text { http://dx.doi.org/10.1016/j.surfcoat.2014.08.077 }}$

To cite this version : Copin, Etienne and Sentenac, Thierry and Le Maoult, Yannick and Blas, Fabien and Ansart, Florence and Vidal, Vanessa and Lours, Philippe Feasibility of luminescent multilayer solgel thermal barrier coating manufacturing for future applications in through-thickness temperature gradient sensing. (2014) Surface and Coatings Technology, vol. 260. pp. 90-96. ISSN 0257-8972

Any correspondance concerning this service should be sent to the repository administrator: staff-oatao@ listes-diff.inp-toulouse.fr 


\title{
Feasibility of luminescent multilayer sol-gel thermal barrier coating manufacturing for future applications in through-thickness temperature gradient sensing
}

\author{
Étienne Copin $^{\mathrm{a}, *}$, Thierry Sentenac ${ }^{\mathrm{a}}$, Yannick Le Maoult ${ }^{\mathrm{a}}$, Fabien Blas ${ }^{\mathrm{a}, \mathrm{b}}$, Florence Ansart ${ }^{\mathrm{b}}$, \\ Vanessa Vidal $^{\text {a }}$, Philippe Lours ${ }^{\text {a }}$ \\ a University of Toulouse, Mines Albi-Institut Clément Ader, Campus Jarlard, F-81013 Albi Cedex 09, France \\ b University of Toulouse, UPS-INP-CNRS, Institut Carnot CIRIMAT, 118 Route de Narbonne,31062, Toulouse, Cedex 09, France
}

\begin{abstract}
A B S T R A C T
This paper investigates the feasibility of manufacturing sol-gel multilayer thermal barrier coatings (TBC) functionalized with different lanthanide ions $\mathrm{Ln}^{3+}$ having distinct photo-luminescence emission wavelengths $(\mathrm{Ln}=\mathrm{Sm}, \mathrm{Eu}, \mathrm{Dy}, \mathrm{Er}, \mathrm{Tm})$ for future applications in temperature gradient sensing. $\mathrm{Ln}^{3+}$ doped $9.75 \mathrm{~mol} \% \mathrm{yttria}$ stabilized zirconia (YSZ) powders were produced to study the effect of activator concentration on luminescence intensity and host matrix crystal structure. Self-quenching was found to limit the maximum signal-to-noise ratio achievable with $\mathrm{Sm}^{3+}, \mathrm{Dy}^{3+}, \mathrm{Er}^{3+}$ and $\mathrm{Tm}^{3+}$ activators, which was not the case for $\mathrm{Eu}^{3+}$ in the 1-10 mol\% range. The increase in activator was found to affect the crystal structure of YSZ. A solution was proposed that suppressed this effect while significantly increasing the luminescence intensity of all activators. Finally a TBC sensor prototype integrating $\mathrm{Eu}^{3+}, \mathrm{Er}^{3+}$ and $\mathrm{Dy}^{3+}$ doped layers distributed throughout the thickness was successfully deposited by a dip-coating sol-gel process and showed promising through-thickness luminescence sensing capabilities.
\end{abstract}

\section{Introduction}

The progressive use and improvement of thermal barrier coatings (TBCs) to protect critical components from heat damage in gas turbines have allowed significant increase in turbine inlet temperature over the last 30 years [1,2]. Today's jet engines' efficiency and durability therefore greatly depend on TBC's reliability and performance. The degradation during service of the current standard 6-8 wt\% yttria stabilized zirconia (YSZ) based TBCs is mainly caused by the initiation and the propagation of microcracks at the interface between either the bond coat and the thermally grown oxide (TGO) or the TGO and the ceramic overcoat resulting from the thermal expansion coefficient mismatch between coatings and substrates [3,4]. This sub-surface mode of failure makes an early detection particularly difficult. The development of reliable predictive models for YSZ overcoat spallation is indeed limited by the difficulty of accessing the effective interface temperature that governs this process through conventional means without compromising the integrity of the coating. This results in strongly conservative margins being imposed to allow safe operation of jet engine turbine components.

From this perspective there has been a growing interest in the application of phosphor thermometry methods for the diagnostic of TBCs as

\footnotetext{
* Corresponding author. Tel.: +33563493282.

E-mail address: etienne.copin@mines-albi.fr (É. Copin).
}

the partial transparency of YSZ in the visible range of the spectrum allows to collect local information conveyed by the luminescence emissions from optically excited luminescent layers integrated throughout the depth of the TBC $[5,6]$. This functionalization can be obtained by the introduction of optically active components such as trivalent lanthanide ions directly into the crystal structure of YSZ, thus without any detrimental alterations of the coating properties [6-8]. Such "sensor TBCs" has shown high potential for measuring substrate/TBC interface temperature $[9,10]$ or investigate local interface delamination $[11,12]$ by non intrusive optical sensing.

Reported here is a feasibility study for the design and manufacturing of multilayer functionalized TBCs, deposited by a dip-coating process from sol-gel precursors, alternative to the standard electron beam physical vapor deposition (EB-PVD) and atmospheric plasma spraying (APS) methods used for YSZ coatings, for future applications in through thickness measuring of temperature gradients. This cost effective process allows one to deposit $9.75 \mathrm{~mol} \%$ porous YSZ TBCs presenting the metastable t' phase with performance under cyclic oxidation comparable to that of EB-PVD coatings $[13,14]$. The easy composition control offered by the technique has already generated interest for manufacturing some high purity YSZ:Er and YSZ:Sm phosphor coatings and powders [15]. Therefore the effect of additions of several dopants including Sm, $\mathrm{Eu}, \mathrm{Dy}, \mathrm{Er}$ and Tm in $9,75 \mathrm{~mol} \% \mathrm{YSZ}$ was investigated, and a solution is proposed for the optimization of YSZ luminescence properties. A prototype of multilayer TBC with three luminescent layers with distinct 
luminescence emissions embedded throughout the thickness, respectively doped with Eu, Er and Dy, was deposited by dip-coating and characterized to assess the feasibility of the process.

\section{Thermal barrier coating sensors}

The health monitoring issues brought by the critical role played by TBCs in the durability of jet engines led to the development of the concept of multifunction TBCs, that combine thermal insulating and optical sensing capabilities. The latter are based on the semi-transparency of zirconia in the visible range and its ability to accept small amounts of trivalent lanthanide ions that substitute for $\mathrm{Zr}^{4+}$ cations in its lattice and act like luminescent activators under appropriate UV or visible illumination (Fig. 1), thus providing information about their local environment. First introduced by Amano et al [16] in 1988, multilayer TBCs alternating various luminescent and undoped layers allow one to evaluate the progression of TBC erosion from the appearance/ extinction of luminescent peaks or directly from evolutions of intensity maps $[17,18]$. Eldridge et al. $[11,12]$ later showed that the effect of reflectance enhanced luminescence, which creates an intensity contrast between metal/YSZ:Eu and air/YSZ:Eu interfaces, can reveal localized delaminated areas at the interface region in APS-TBCs integrating a 7$10 \mu \mathrm{m}$ luminescent sublayer. Finally the application of phosphor thermometry methods $[19,20]$, mainly based on the dependence of luminescence intensity and decay time on temperature, allows nonintrusive optical sensing of buried luminescent layers to determine through-thickness temperature. Application to bilayer systems such as YSZ:Dy/YSZ [9,21] and YSZ:Eu/YSZ [10] has thus allowed measurements of substrate/YSZ interface temperature. The existence of several dopants with distinct luminescence emission peaks suggests that more complex layered TBC architectures, also referred by Gentleman and al. [6] as "rainbow sensors", could be powerful tools to measure the complete temperature gradient or heat flux across TBCs. Fig. 1 presents the luminescence spectra of the various luminescent activators in 9.75-YSZ selected for this work on the basis of their luminescence properties and performance as thermographic phosphors either in YSZ or other matrices. Several doublets and triplets of compatible activators such as Tm-Er-Eu or Dy-Er-Eu are thus indentified as valid candidates to build multiwavelength TBCs sensors for through thickness health and temperature monitoring. It should be born in mind that although $\mathrm{Dy}^{3+}$ and $\mathrm{Tm}^{3+}$ appear to have distinct emissions, thermalization of the ${ }^{4} \mathrm{I}_{15 / 2}$ level of $\mathrm{Dy}^{3+}$ at high temperature will generate an additional peak at $458 \mathrm{~nm}$ potentially overlapping the peaks of $\mathrm{Tm}^{3+}$ [22], limiting to three the number of functionalized

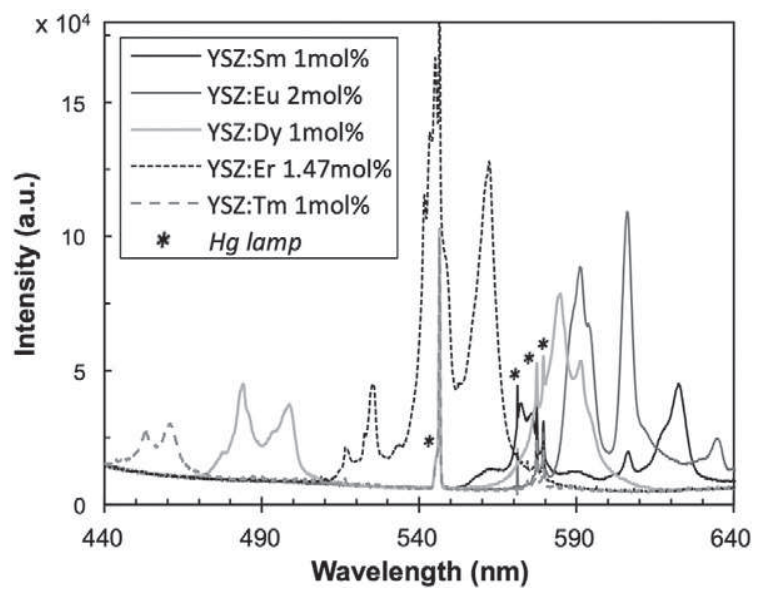

Fig. 1. Luminescence spectra in the visible range for various lanthanide-doped 9.75 mol\%-YSZ:Ln phosphors ( $\mathrm{Ln}=\mathrm{Sm}$, Eu, Dy, Er and Tm) under long wave UV illumination from a mercury vapor lamp $(365 \mathrm{~nm})$. The content of $\mathrm{Sm}^{3+}, \mathrm{Dy}^{3+}, \mathrm{Er}^{3+}$ and $\mathrm{Tm}^{3+}$ activators correspond to the concentration for which the maximal intensity is achieved. luminescent layers that could be used for this range of activators. Of all dopants presented in Fig. $1, \mathrm{Eu}^{3+}, \mathrm{Er}^{3+}$ and $\mathrm{Dy}^{3+}$ exhibit the brightest luminescence in YSZ in addition to having distinct emission peaks in the red, green and blue region of the visible spectrum respectively, that therefore make them the best candidates for the design and the manufacturing of a multilayer TBC sensor prototype.

\section{Experimentation}

\subsection{Synthesis of YSZ phosphors}

YSZ phosphor powders $\left(9.75 \mathrm{~mol} \% \mathrm{YO}_{1.5}\right.$ ) with contents of $\mathrm{LnO}_{1.5}$ $(\mathrm{Ln}=\mathrm{Eu}, \mathrm{Er}, \mathrm{Dy}, \mathrm{Sm}$ or Tm) between 0.15 and 10 at\% were synthesized using the sol-gel route [23]. The sols were prepared by mixing zirconium (IV) propoxide $(\mathrm{Zr}(\mathrm{OPr}) 4)$ (Sigma Aldrich) and appropriate contents of yttrium (III) and Ln (III) nitrates (Sigma Aldrich) as precursors in a solution of 1-propanol (Sigma Aldrich) and ultrapure water. Acetylacetone (AcAc) (Sigma Aldrich) was used as a complexing agent to control the kinetics of hydrolysis of the zirconium alkoxide [24]. The volume rates of $\left[\mathrm{AcAc} / \mathrm{Zr}(\mathrm{OPr})_{4}\right]$ and $\left[\mathrm{H}_{2} \mathrm{O} / \mathrm{Zr}(\mathrm{OPr})_{4}\right]$ were kept constant at 0.8 and 9.5 respectively. More details about the preparation of the mixtures from the reagents can be found in reference [23]. After 30 min of mechanical stirring the solutions were then held for one night $(\sim 16 \mathrm{~h})$ at $50{ }^{\circ} \mathrm{C}$ to accelerate the hydrolysis and condensation of the sols into bright monolith gels free of precipitates. The solvent was then evaporated in a drying oven at $70{ }^{\circ} \mathrm{C}$. The resulting dried gels, called xerogels, were subsequently calcined for $2 \mathrm{~h}$ at $800{ }^{\circ} \mathrm{C}$ to remove the remaining traces of solvents and then manually ground to powders for $4 \mathrm{~min}$. The products obtained at this stage are white powders consisting in 2-50 $\mu \mathrm{m}$ particles of partially crystallized YSZ. An additional heat treatment of the powders at $1100{ }^{\circ} \mathrm{C}$ for $2 \mathrm{~h}$ ensured the full crystallization of the YSZ into metastable quadratic phase $t$ ' or cubic phase $\mathrm{c}$ depending on their composition.

\subsection{Deposition of TBC sensors}

Multilayer TBC sensor prototypes containing luminescent layers of composition $\operatorname{Ln}_{\mathrm{x}}^{\prime} \mathrm{Y}_{0.0975-\mathrm{x}} \mathrm{Zr}_{1-0.092-\mathrm{x}} \mathrm{O}_{1.951-2 \mathrm{x}}\left(\mathrm{Ln}^{\prime}=\mathrm{Eu}\right.$, Er or Dy) with distinct emissions wavelengths were shaped by a dip-coating process previously developed $[14,15]$.

First YSZ aerogel powders were synthesized from a sol-gel protocol adapted from Lecompte et al. [25]. Rare earth doped YSZ gels were prepared as described in part 3.1 but were dried above the supercritical point of 1-propanol $\left(\mathrm{T}_{\mathrm{C}}=261{ }^{\circ} \mathrm{C} ; \mathrm{P}_{\mathrm{C}}=5.1 \mathrm{MPa}\right)$ in a stainless steel autoclave (Paar Instrument 4621) instead of being dried in free air. Temperature was kept constant at $270{ }^{\circ} \mathrm{C}$ and pressure at $9 \mathrm{MPa}$ for $1 \mathrm{~h}$, afterwards the solvent was slowly released in isothermal conditions. The resulting brittle monolithic aerogels whose structure is similar to that of the wet gels were calcined for $2 \mathrm{~h}$ at $700{ }^{\circ} \mathrm{C}$ and ball milled at $250 \mathrm{rpm}$ for $1 \mathrm{~h}$ in an agate mortar to obtain highly porous powders having morphological and grain size characteristics more suitable for dispersion and deposition by dip-coating than xerogel powders obtained through conventional drying at atmospheric pressure [23,26].

The substrates used for the depositions were AM1 single crystal nickel based superalloy coupons coated with $\mathrm{Ni}(\mathrm{Pt}, \mathrm{Al})$ bondcoat, previously sand blasted with $10 \mu \mathrm{m}$ corindon particles and preoxidized for $2 \mathrm{~h}$ at $950{ }^{\circ} \mathrm{C}$ under a $\mathrm{O}_{2}$ pressure of $0.05 \mathrm{~Pa}$. Slurries were prepared by mixing $20 \mathrm{wt} \%$ of YSZ sol with YSZ aerogel powder previously dispersed in 1-propanol with polyvinylpyrrolidone 3500 (PVP) (Acros Organics) dispersing agent. The depositions were carried out at room temperature by dipping the substrates in the slurry with a controlled withdrawal rate of $250 \mathrm{~mm} / \mathrm{min}$ to ensure the deposition of a $\sim 10$ $15 \mu \mathrm{m}$ thick layer at each dip procedure. The deposited films were then dried for $5 \mathrm{~min}$ at $50{ }^{\circ} \mathrm{C}$ before implementing the next dip-coating.

Coatings of final thickness in the range of 100-150 microns were obtained after 13 successive dips. Multilayer prototypes alternating 


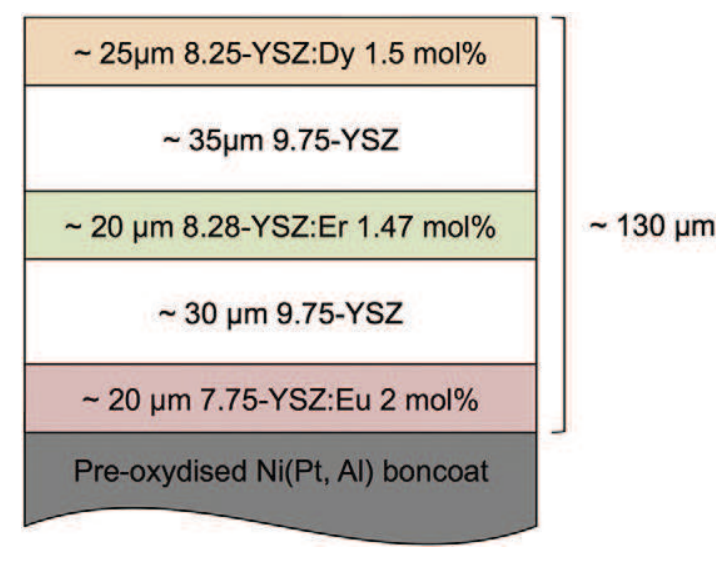

Fig. 2. Schematic representation of a deposited multilayer TBC sensor prototype.

luminescent and unmodified YSZ layers such as shown in Fig. 2 were built by successive dipping into slurries with different compositions. Subsequently, samples were sintered for $2 \mathrm{~h}$ at $1100{ }^{\circ} \mathrm{C}$. The heating and cooling rates were set at $50{ }^{\circ} \mathrm{C} / \mathrm{h}$ to minimize thermal stresses caused by the mismatch between the thermal expansion coefficients of the coating and the substrate.

\subsection{Characterization}

The luminescence spectra of both powders and coatings were recorded at room temperature over the $400-700 \mathrm{~nm}$ range with an Ocean Optics USB2000 spectrometer equipped with a $1000 \mu \mathrm{m}$ optical fiber. A Philips TL 6 W BLB mercury vapor lamp (main UV emission peak at $365 \mathrm{~nm}$ ) and a $1.1 \mathrm{~W}$ continuous wave diode pumped solid state green laser operating at $532 \mathrm{~nm}$ (CNI laser) were used as excitation sources of the phosphors. A color CCD camera (AVT PIKE F-145C) was used to record images of the luminescence intensity emitted by the embedded luminescent sublayers. A narrow band interference filter centered at $636 \mathrm{~nm}$ (FWHM $\sim 10 \mathrm{~nm}$ ) was also used to filter the luminescence signal from the YSZ:Eu ${ }^{3+}$ layer.

Structural analysis of YSZ powders and coatings were performed by $\mathrm{X}$-rays diffraction (XRD) measurements. XRD patterns were collected by scanning the angular range from $25^{\circ}$ to $100^{\circ}$ with a PANalytical $X$ 'Pert diffractometer equipped with a X'Celerator linear detector using $\mathrm{Cu} \mathrm{K} \mathrm{K}_{\alpha}\left(\lambda\left(\mathrm{CuK}_{\alpha 1}\right)=1.5406 \AA ; \lambda\left(\mathrm{CuK}_{\alpha 2}\right)=1.5445 \AA\right)$ as the $\mathrm{X}$ ray source. The operating voltage and currents were respectively $45 \mathrm{kV}$ and $40 \mathrm{~mA}$, with a step size of $0.08^{\circ} 2 \theta$ and a step time of $0.25 \mathrm{~s}$. The determination of crystal parameters was performed by Rietveld refinement $[27,28]$ of the DRX patterns with the commercial software PANalytical X'Pert HighScore Plus using the $\mathrm{P}_{2} / \mathrm{mcn}$ and Fm $3 \mathrm{~m}$ space groups for the quadratic and cubic phases respectively. Scanning electron microscope (SEM) observations of the powders and coatings cross sections were achieved using a FEI Nova Nanosem 450 field emission gun scanning electron microscope (FEG-SEM) operating at an accelerating voltage of $10 \mathrm{kV}$. The position and thickness of the different layers were determined from energy-dispersive X-ray (EDX) measurements performed on multilayer coating cross sections with the same SEM.

\section{Results and discussion}

\subsection{Effects of luminescent activators concentration}

The significant reduction of the luminescence intensity combined with the increasing interferences caused by thermal radiations at temperatures above $1000{ }^{\circ} \mathrm{C}$ are critical issues limiting signal-to-noise ratio in high temperature luminescence thermometry $[20,29,30]$. It is therefore of utmost concern to choose judicious activator concentration ranges so that the selected phosphors show strong luminescence, although the range of concentrations for which the lifetime decay exhibits appropriate variations with temperature may warrant the use of a different strategy. Increased non-radiative interactions between activators can indeed cause shortening of the lifetime or lead to decay times with complex waveform that can make the processing of the data for luminescence lifetime analysis more difficult $[7,19]$. The introduction of activator species within the host lattice must also remain non intrusive to avoid detrimental effects on the desired primary properties of the host material. In order to study the effect of activator concentration on luminescence performance and crystal structure, 9.75-YSZ-type phosphors xerogel powders with various contents of $\mathrm{SmO}_{1.5}$, Eu O $\mathrm{O}_{1.5}$, Dy $\mathrm{O}_{1.5}, \mathrm{Er} \mathrm{O}_{1.5}$ and $\mathrm{Tm} \mathrm{O}_{1.5}$ were synthesized. The xerogel route was chosen for convenience as the process is more suitable for the production of a large quantity of small batches. Although there are some differences in terms of particles morphology and distribution with aerogel powders used for TBC deposition, the relative effect of activator composition on luminescence and crystal structure is expected to remain the same [23].

\subsubsection{Effects on luminescence intensity}

Fig. 1 gives a representative example of the luminescence spectra from the different phosphors under continuous long-wave UV illumination of a mercury vapor lamp (365 nm). As the concentration in trivalent lanthanide ion activators was modified the only change observed in the luminescence spectra, not shown here, was the evolution of the intensities of the main luminescence peaks. This evolution is plotted in Fig. 3. The intensities of the main peaks were normalized by the corresponding maximum intensity in each spectrum. 9.75-YSZ phosphors doped with Dy, Sm, Er and Tm all exhibit an optimum of the intensity of the luminescence peaks for concentrations between 1 and 1.63 at\%, after which further increases in activator content lead to lower intensities as a result of an increase of radiationless energy transfers between close neighboring dopant ions, a process also referred to as concentration quenching or self-quenching. The plotted lines in Fig. 3 represent the fit of the experimental data points with the direct excitation, self-quenching model by Johnson-Williams $[31,32]$ relating the luminescence efficiency $\eta$ of the activator (assumed to be proportional to the observed relative intensity) and the activator concentration $C$ by the expression

$$
\eta=\frac{C(1-C)^{Z}}{C+\frac{\sigma}{\sigma^{\prime}}(1-C)} .
$$

$\mathrm{Z}$ and $\sigma / \sigma$ are two fitting parameters, the former standing for the number of lattice positions (intersticial or substitutional) in the vicinity of an activator ion such that if another activator occupies one of these positions no luminescence will occur, and the latter standing for the ratio of the capture cross sections of photons by the host lattice and the activators.

The values obtained typically between $17-30$ and $0.003-0.007$ for $Z$ and $\sigma / \sigma$ respectively are consistent with reported values in the literature for YSZ:Ln type phosphors [6]. Luminescence output of these phosphors can thus be optimized with relatively limited composition modifications of the host material. The spectra given as an example in Fig. 1 provide a comparison of the luminescence strength of the different dopants $\mathrm{Sm}^{3+}, \mathrm{Dy}^{3+}, \mathrm{Er}^{3+}$ and $\mathrm{Tm}^{3+}$ at their optimal concentration in 9.75 at\% YSZ mentioned above. Interestingly one can notice that $\mathrm{Er}^{3+}$ appears to emit a significantly brighter intensity than $\mathrm{Dy}^{3+}, \mathrm{Sm}^{3+}$ and $\mathrm{Tm}^{3+}$ respectively in that particular host matrix.

It can be noticed in Fig. 3.d that conversely to the other activators no self-quenching of luminescence is observed for YSZ:Eu in the 1-10 at\% range, for which the luminescence intensity of the spectral lines is observed to linearly increase by one order of magnitude in that range. This behavior can be explained by the difference in self-quenching 

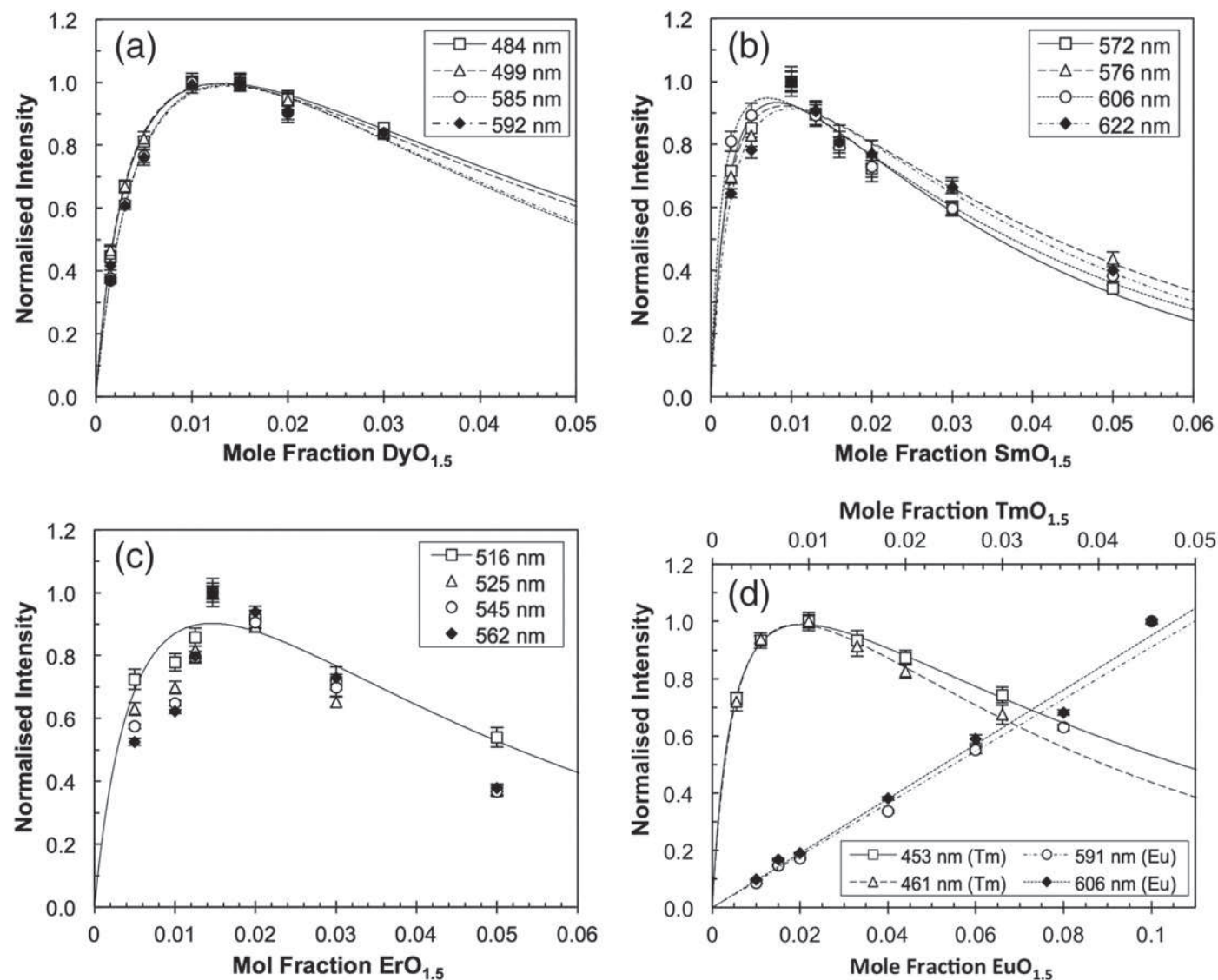

Fig. 3. Evolution of the intensities of the main luminescence peaks normalized by the corresponding maximum intensity for each spectrum with the concentration of a) DyO $\mathrm{H}_{1.5}$, b) $\mathrm{Sm}_{1.5}$, c) Er $\mathrm{O}_{1.5}$, d) $\mathrm{Eu} \mathrm{O}_{1.5}$ and $\mathrm{Tm} \mathrm{O}_{1.5}$ in 9.7at\% YSZ xerogel powders. Plotted lines correspond to the fit of the experimental data points with the Johnson-Williams model [31,32] (Eq. (1)).

properties between $\mathrm{Eu}^{3+}$ ions and the other dopants investigated. While the presence of intermediary states between the initial excited state and the ground state in the energy level distribution of $\mathrm{Er}^{3+}$, $\mathrm{Sm}^{3+}, \mathrm{Dy}^{3+}$ and $\mathrm{Tm}^{3+}$ favors self-quenching at relatively low concentrations by cross relaxation, the large gap in energy between the top ${ }^{5} \mathrm{D}_{0}$ emitting level from which the $591 \mathrm{~nm}$ and $606 \mathrm{~nm}$ are originated $(\sim 17$ $\left.250 \mathrm{~cm}^{-1}\right)$ and the top of the ${ }^{7} \mathrm{~F}_{6-0}$ ground multiplet $\left(\sim 5000 \mathrm{~cm}^{-1}\right)$ of $\mathrm{Eu}^{3+}$ electronic structure makes concentration quenching by this multipolar transfer process considerably less probable [7,33-35]. The selfquenching of $\mathrm{Eu}^{3+}$ rather occurs by non-resonant transfer interactions strongly dependent upon crystal structure [33] and is not expected to occur in a YSZ matrix at concentrations below 10 at\% [36]. Therefore intensity emissions up to more than 4 times that of other activators can be achieved with a $10 \mathrm{~mol} \%$ addition of $\mathrm{Eu}^{3+}$. Since $\mathrm{Eu}^{3+}$ can also stabilize the desirable metastable tetragonal phase $\mathrm{t}^{\prime}$ of $\mathrm{ZrO}_{2}$ in the same way as $\mathrm{Y}^{3+}$ does [37-39] it potentially offers more flexibility for the design of strongly emitting YSZ phosphors, although it might be limited by the potential effect of high concentration on luminescence, known to lead to quicker and more complex luminescence lifetime decays $[7,19]$. This latter aspect is still currently under investigation for the range of phosphors presented here.

\subsubsection{Effects on YSZ crystal structure}

The crystal structure of the various phosphor powders doped with $\mathrm{Sm}^{3+}, \mathrm{Eu}^{3+}, \mathrm{Dy}^{3+}, \mathrm{Er}^{3+}$ and $\mathrm{Tm}^{3+}$ was investigated by X-Ray diffraction (XRD). Fig. 4.a shows the three diffraction patterns of both undoped and $\mathrm{Er}^{3+}$ doped 9.75-YSZ xerogel powders in the $\left[30^{\circ}-100^{\circ}\right] 2 \theta$ range. The diffraction peaks observed on the un-doped YSZ pattern and the calculated c/a $\sqrt{ } 2$ of 1.0096 correspond to the metastable t' crystal structure expected for YSZ with this composition prepared by this sol-gel route $[23,40]$. The diffraction patterns of powders doped with
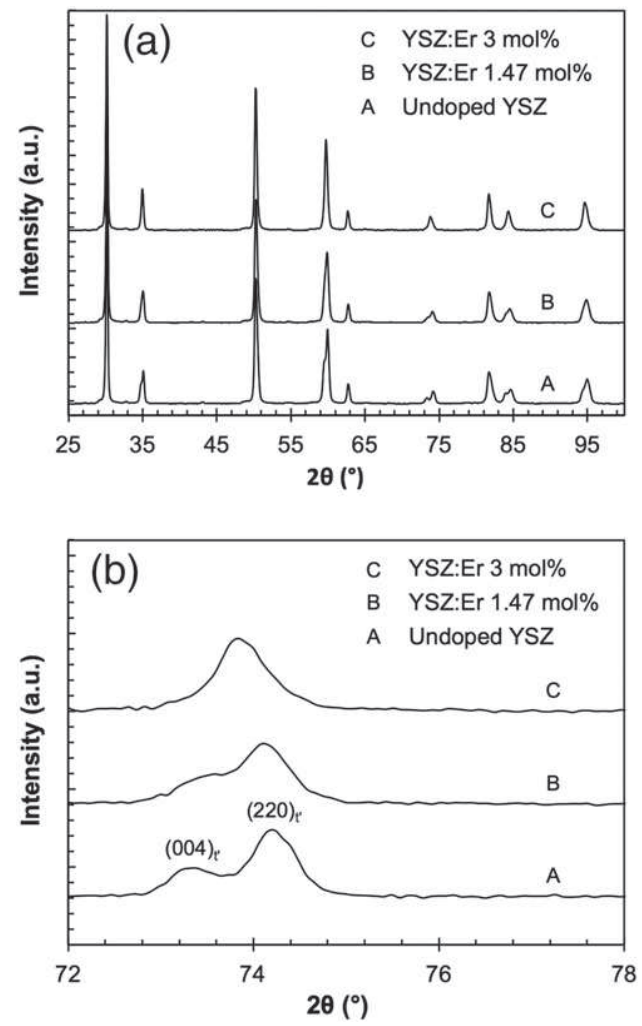

Fig. 4. Diffraction patterns for $9.7 \mathrm{~mol} \% \mathrm{YSZ}$ :Er powders with increasing content of $\mathrm{Er} \mathrm{O}_{1.5}$ a) across the complete angular range, b) limited to the $72-78^{\circ}$ range. 
1.47 and $3 \mathrm{~mol} \%$ confirm that they also crystallize in the t' structure. However some changes are noticeable for some of the high angle peaks. In particular it can be observed in Fig. 4.b that the angular distance between the (004) $)^{\prime}$ and $(220)_{t}$ reflections of the $t^{\prime}$ phase initially at $73.2^{\circ}$ and $74.3^{\circ}$ tends to decrease with increasing Er content. These

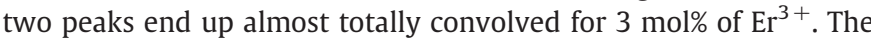
same observation is made for the doublets of peaks at $35,60^{\circ}$ and $84^{\circ}$ $2 \theta$ angles. These results indicate that the material tends towards a cubic structure [40,41], a tendency also observed for similar concentrations in the Sm, Eu, Dy and Tm doped YSZ powders.

The evolution of the $\mathrm{c} / \mathrm{a} \sqrt{ } 2$ values calculated from the refinement of the spectra by the Rietveld method reported in Fig. 5 is consistent with these observations. For all dopants the $\mathrm{c} / \mathrm{a} \sqrt{ } 2$ ratio decreases linearly from the initial value of 1.0096 to nearly one in the range 0.5-6 mol\%, as the quadratic phase progressively turns into the undesirable cubic phase. Finally, a single cubic phase is obtained for powders with $\mathrm{Eu}^{3+}$ content above 6 mol\%, and the trends observed in Fig. 5 suggest that a single cubic phase would be obtained with similar contents of $\mathrm{Sm}^{3+}$, $\mathrm{Dy}^{3+}, \mathrm{Er}^{3+}$ or $\mathrm{Tm}^{3+}$. This linear decrease of the $\mathrm{c} / \mathrm{a} \sqrt{ } 2$ ratio from 1.01 to 1 is typically reported in the literature for $\mathrm{ZrO}_{2}$ doped with more than $10 \mathrm{~mol} \%$ of $\mathrm{YO}_{1.5}$, the minimum amount to ensure complete stabilization of the cubic phase being around 15 to $16 \mathrm{~mol} \%[23,40]$. These values are close to the corresponding 15.75 at\% overall dopant concentration $\left(\mathrm{YO}_{1.5}+\mathrm{EuO}_{1.5}\right)$ required to fully stabilize the cubic phase in the 9.75-YSZ: $\mathrm{Eu}^{3+}$ phosphor powders presented here. Therefore it is concluded that the significant impact on the tetragonality of the quadratic phase at the relatively low concentrations required for optimizing luminescence intensity (1-1.63 mol\%) is rather an effect of the overall substitution of $\mathrm{Zr}^{4+}$ by trivalent ions having larger ionic radius than an effect of the specific nature of the dopants. The functionalization of 9.75-YSZ without significant alteration of the sought crystal structure for TBC applications is thus limited by the already high content of $\mathrm{YO}_{1.5}$ necessary to stabilize the desirable metastable tetragonal phase t'. This is particularly limiting for YSZ:Eu ${ }^{3+}$ that was shown to exhibit large increases in luminescence intensity in the range of 1-10 $\mathrm{mol} \%$, for which compromises appear to be necessary for a good balance between luminescent and structural properties.

\subsection{Optimization of YSZ phosphors}

In order to minimize the impact of rare earth additions in YSZ crystal structure, it was proposed to keep constant the overall dopant content in the lattice, i.e. to partially substitute the $\mathrm{Y}^{3+}$ stabilizing ions by luminescent markers. This solution was motivated by the fact that a minimum of $8 \mathrm{~mol} \% \mathrm{YO}_{1.5}$ only is necessary for the synthesis of quadratic zirconia by the sol-gel route used in this work [40] and by the $\mathrm{t}^{\prime}-\mathrm{ZrO}_{2}$ stabilizing ability-reported by various authors [37-39,42,43]-of some

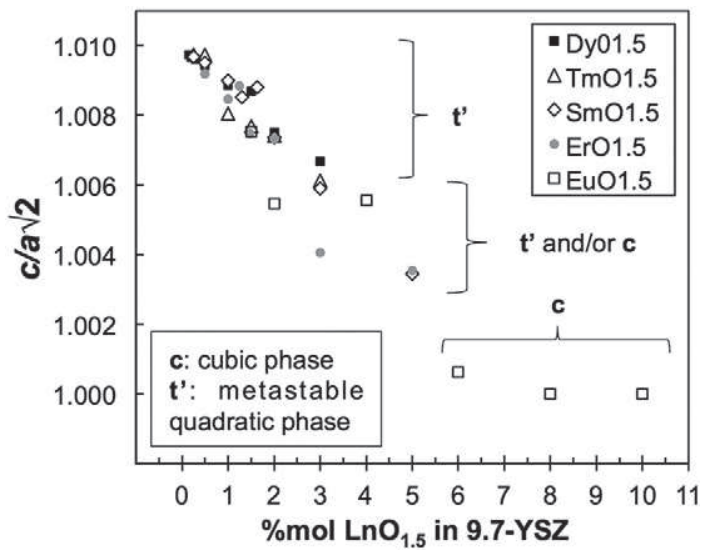

Fig. 5. Evolution of the tetragonality coefficient $\mathrm{c} / \mathrm{a} \sqrt{ } 2$ with $\mathrm{LnO}_{1.5}$ content $(\mathrm{Ln}=\mathrm{Sm}$, Eu, Dy, Er or Tm) in $\mathrm{ZrO}_{2}$ already containing $9.75 \mathrm{~mol} \%$ of $\mathrm{YO}_{1.5}$. of these elements such as $\mathrm{Eu}^{3+}$ or $\mathrm{Dy}^{3+}$. The XRD patterns in the $2 \theta$ range $70-90^{\circ}$ of 9.75 -YSZ and 7.75 -YSZ powders containing $2 \mathrm{~mol} \%$ $\mathrm{Eu}^{3+}$ are compared to that of un-doped YSZ in Fig. 6. As seen previously in part 4.1.2, additions of $2 \mathrm{~mol} \%$ of Eu to 9.75-YSZ cause a significant distortion of the unit cell, illustrated in Fig. 6 by the convolution of the $(004)_{\mathrm{t}^{\prime}}$ and $(220)_{\mathrm{t}^{\prime}}$ diffraction peaks at $74^{\circ}$ as well as the low value of the calculated $c / a \sqrt{ } 2$ ratio (1.0055). This effect is suppressed by the substitution of $2 \mathrm{~mol} \%$ of $\mathrm{Y}^{3+}$ by the same amount of $\mathrm{Eu}^{3+}$, that thus preserves a t' phase presenting a $\mathrm{c} / \mathrm{a} \sqrt{2}$ ratio (1.0105) very close to that of the non-functionalized material (1.0102). Furthermore, further increasing the substitution rate to $4 \mathrm{~mol} \%$ also appears to have very little additional effects on the crystal structure, suggesting the suitability of this solution for the fabrication of high luminescence efficiency YSZ:Eu phosphors. The crystal lattice parameters calculated for all the YSZ:Ln aerogel phosphor powders investigated are displayed in Table 1, and the comparison with that of un-doped 9.75YSZ powder confirms the relevance of $\mathrm{Y}^{3+}$ partial substitution for minimizing the impact of activator introduction on the microstructure $(\mathrm{c} / \mathrm{a} \sqrt{2}$ ratios close to 1.01). Finally the luminescence spectra presented in Fig. 7 illustrate a quite interesting side effect of $\mathrm{Y}^{3+}$ substitution by $\mathrm{Ln}^{3+}$. Indeed lowering the $\mathrm{Y}^{3+}$ content by $2 \mathrm{~mol} \%$ generates a $53 \%$ increase of the maximum peak intensity of the ${ }^{5} \mathrm{D}_{0} \rightarrow{ }^{7} \mathrm{~F}_{1}(591 \mathrm{~nm})$ and ${ }^{5} \mathrm{D}_{0} \rightarrow{ }^{7} \mathrm{~F}_{2}$ $(606 \mathrm{~nm})$ transitions in YSZ:Eu $2 \mathrm{~mol} \%$ aerogel powders. This effect appears to be dependent on $\mathrm{Y}^{3+}$ concentration as observations on 5.75-YSZ:Eu $4 \mathrm{~mol} \%$ showed that the intensity corresponding to the above mentioned transitions increased by more than $60 \%$. It was also observed that the emissions of all the other activators investigated (Table 1) are also enhanced by 8 to $30 \%$, depending on the nature of the activator and the luminescence peak. At this stage it is still unclear whether this effect is related to the quenching of the luminescence by the $\mathrm{Y}^{3+}$ ions (or the associated oxygen vacancies), or is the result of changes in the optical properties of the host material in the emitting/ excitation range of the rare earth activators (transmission, absorption).

\subsection{Characterization of a multilayer TBC sensor prototype}

To investigate the feasibility of multilayer TBC sensor manufacturing from sol-gel precursors, 100 to $150 \mu \mathrm{m}$ thick prototypes containing three thin luminescent layers with distinct emissions wavelengths (respectively doped with $\mathrm{Eu}^{3+}, \mathrm{Er}^{3+}$ an $\mathrm{Dy}^{3+}$ ) distributed throughout the thickness were deposited on nickel superalloy coupons by dip-coating (Fig. 2). After sintering at $950{ }^{\circ} \mathrm{C}$ for 2 hours, smooth and uniform white coatings were obtained. XRD analysis confirmed that they all possess the desired metastable quadratic $\mathrm{t}$ ' structure with a $\mathrm{c} / \mathrm{a} \sqrt{ } 2$ ratio of 1.0104. Fig. 8 shows SEM cross-section micrographs of a representative $100 \mu \mathrm{m}$ prototype. The coating presents the typical microstructure of a sol-gel TBC consisting of a highly porous network of aerogel particles issued from the initial slurry bonded together by the crystallized sol (Fig. 8.b). The isotropic nature of the resulting porosity is believed to

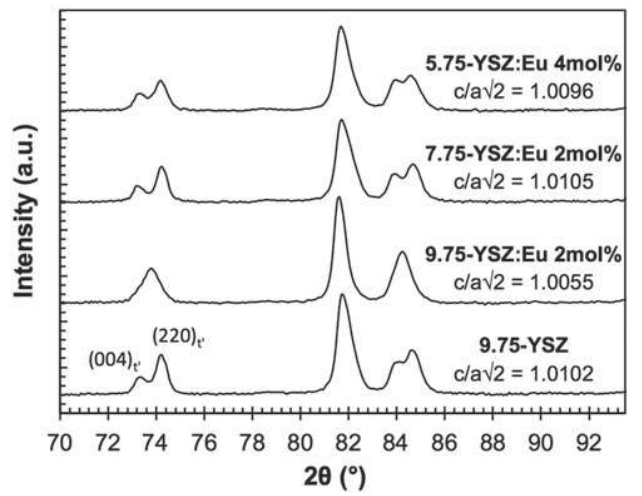

Fig. 6. XRD patterns of various YSZ:Eu powders illustrating the effect of partial substitution of $\mathrm{YO}_{1.5}$ by $\mathrm{EuO}_{1.5}$ on $\mathrm{YSZ}$ crystal structure. 
Table 1

Crystal lattice parameters of various YSZ:Ln aerogel powders ( $\mathrm{Ln}=\mathrm{Sm}, \mathrm{Eu}, \mathrm{Dy}$, Er or Tm) determined by the Rietveld method from XRD spectra.

\begin{tabular}{llll}
\hline Material & $\mathrm{a}$ and $\mathrm{b}(\AA)$ & $\mathrm{c}(\AA)$ & $\mathrm{c} / \mathrm{a} \sqrt{ } 2$ \\
\hline 9.75-YSZ & 3.6137 & 5.1625 & 1.0102 \\
8.12-YSZ:Sm 1.63 mol\% & 3.6153 & 5.1656 & 1.0103 \\
7.75-YSZ:Eu 2 mol\% & 3.6154 & 5.1664 & 1.0105 \\
8.25-YSZ:Dy 1.5 mol\% & 3.6134 & 5.1640 & 1.0106 \\
8.28-YSZ:Er 1.47 mol\% & 3.6135 & 5.1623 & 1.0102 \\
8.25-YSZ:Tm 1.5 mol\% & 3.6133 & 5.1617 & 1.0101 \\
\hline
\end{tabular}

provide a good balance between thermal insulation and thermomechanical strength $[13,14,44]$.

The position and thickness of the different layers determined by EDX analysis are indicated in Fig. 8.a. There were no signs of adherence loss or crack initiation and propagation at interfaces between layers or between the substrate and the deposit, indicating the satisfactory sintering of the coating as a morphologically uniform single layer well adherent to the substrate. The main concern regarding the design of TBC sensor is the individual thickness and thickness uniformity of the luminescent layers. Since TBCs are subject to large thermal gradients, uniform sensing layer thicknesses of about $10 \mu \mathrm{m}$ of below are to be preferred to avoid significant errors in the temperature readings [20]. There are in general little thickness variations within each layers, although the presence of some large particles (dimensions $>15-30 \mu \mathrm{m}$ ) can locally disturb the layers' uniformity and density, either because of their large dimension or by contributing to the creation of large pores. However it should be noticed that the upper layers present a significantly larger thickness than the lower ones for the same deposition conditions, as the increase of the viscosity of the sol with time results in some noticeable film thickening with increasing number of dips. Nevertheless this effect can be easily controlled by adapting the number of dips for each layer or the withdrawal speed.

Fig. 9 presents the luminescence spectra of a coating under continuous UV illumination. The peaks corresponding to the YSZ:Dy top layer are clearly visible at $584-590 \mathrm{~nm}$ and $480-496 \mathrm{~nm}$. However, the two doublets of peaks corresponding to the luminescent transitions in $\mathrm{Er}^{3+}$ at 516-524 nm and 544-561 nm are barely distinguished from the background, and no luminescence peaks from the YSZ:Eu layer are observed. Indeed the low power UV illumination source, that emits in a low transmission range of YSZ (365 nm) [5,6], does not provide enough energy to the deepest layers to either excite the activators or generate a sufficiently strong luminescence output from the coating. Fig. 10 shows a filtered image of the TBC prototype under the illumination of a continuous high power laser operating at $532 \mathrm{~nm}$, a wavelength that allows to stimulate both $\mathrm{Er}^{3+}$ and $\mathrm{Eu}^{3+}$ luminescence [6]. Although the ${ }^{5} \mathrm{D}_{0} \rightarrow{ }^{7} \mathrm{~F}_{3}$ transition of $\mathrm{Eu}^{3+}$ at $636 \mathrm{~nm}$, on which is

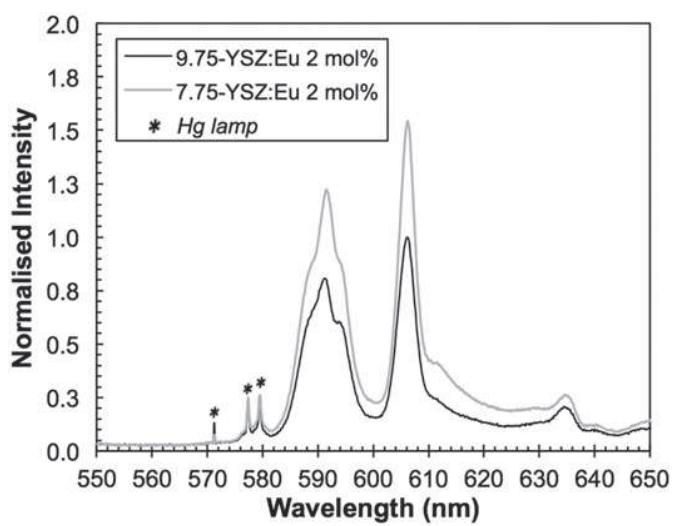

Fig. 7. Luminescence spectra of YSZ:Eu powders illustrating the increase of luminescence intensity with partial substitution of $\mathrm{YO}_{1.5}$ by $\mathrm{EuO}_{1.5}$ in $\mathrm{YSZ}$ :Eu phosphors.
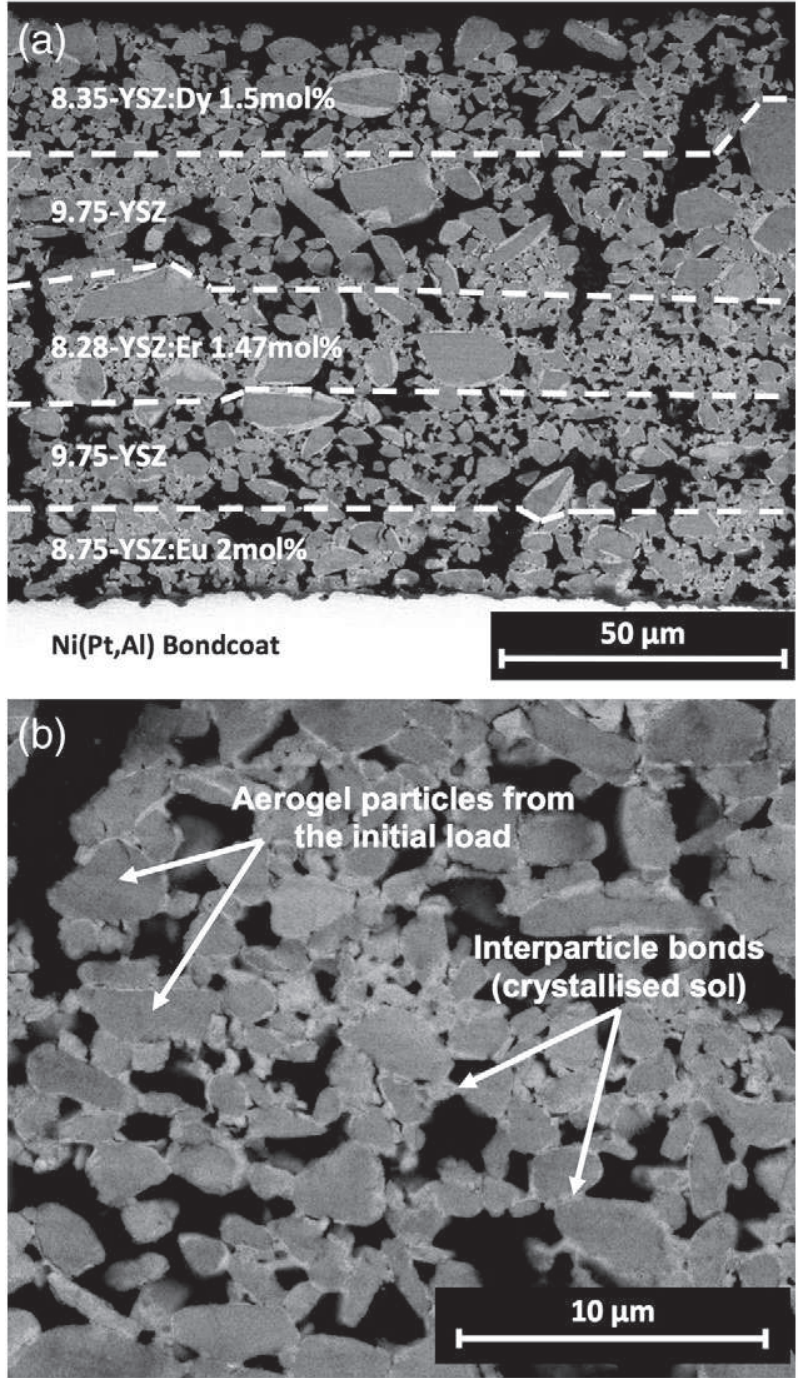

Fig. 8. a) SEM micrograph of a Eu-Er-Dy functionalized multilayer TBC sensor prototype cross section and b) details showing aerogel particles and interparticle bonding.

centered the narrowband filter used, is 4 times less bright than the ${ }^{5} \mathrm{D}_{0} \rightarrow{ }^{7} \mathrm{~F}_{2}$ emission line at $606 \mathrm{~nm}$, the luminescence of the YSZ:Eu ${ }^{3+}$ layer at the interface with the bond coat is clearly visible. These results confirm the successful deposition of a TBC with luminescence sensing properties throughout the whole thickness.

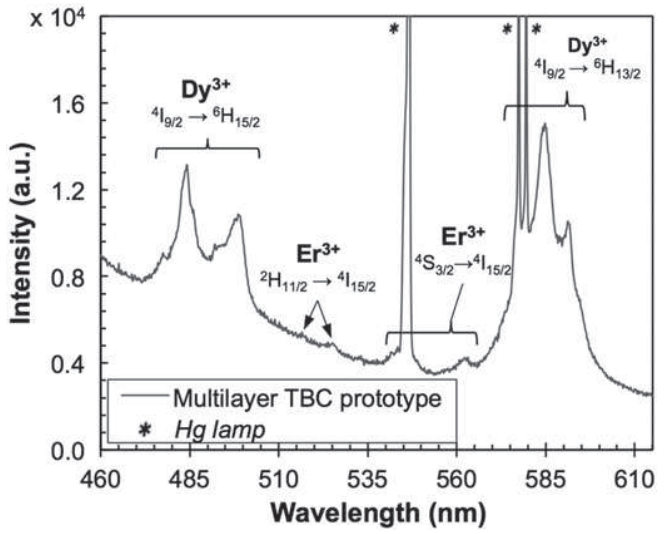

Fig. 9. Luminescence spectra of a Eu-Er-Dy functionalized multilayer TBC sensor prototype under continuous UV illumination (365 nm). 


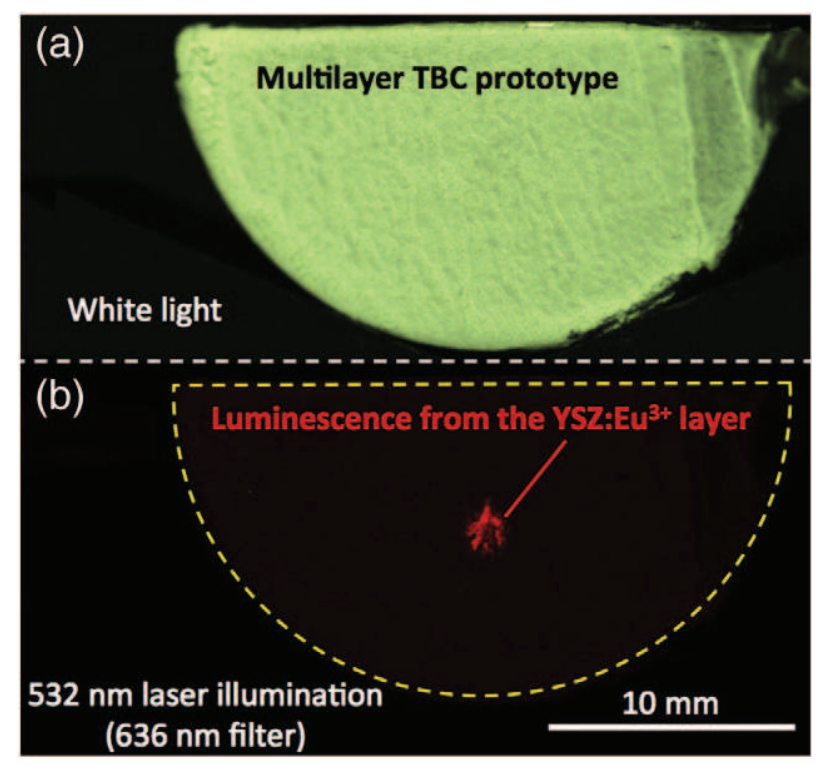

Fig. 10. Images of a multilayer $T B C$ prototype (a) under white light illumination, (b) illuminated with a $532 \mathrm{~nm}$ laser showing the luminescence intensity at $636 \mathrm{~nm}$ from the YSZ: $\mathrm{Eu}^{3+}$ layer located at the interface with the bond coat.

\section{Conclusion}

Over the last decade non-contact phosphor thermometry methods applied to standard TBC systems have shown their relevance for accessing the temperature of a luminescent sub-surface YSZ layer functionalized with $\mathrm{Eu}^{3+}$ and $\mathrm{Dy}^{3+}$ activators [9,10]. 9.75-YSZ:Ln ( $\mathrm{Ln}=\mathrm{Sm}$, $\mathrm{Eu}, \mathrm{Dy}, \mathrm{Er}, \mathrm{Tm}$ ) phosphor powders have been successfully synthesized by the sol-gel route, and the influence of activator concentration on luminescence intensity and crystal properties was studied. The luminescence of $\mathrm{Sm}^{3+}, \mathrm{Dy}^{3+}, \mathrm{Er}^{3+}$ and $\mathrm{Tm}^{3+}$ is quenched due to energy interactions between activator ions for contents around 1-1.5 mol\%, limiting the maximum intensity achievable to that optimum. On the other hand the luminescence intensity of $\mathrm{Eu}^{3+}$ ions increases linearly by an order of magnitude in the 1-10 mol\% range, exceeding significantly that of other activators at high content (up to 4 times at $10 \mathrm{~mol} \%$ ). However high overall content of $\mathrm{Zr}^{4+}$ substitution with $\mathrm{Y}^{3+}$ and $\mathrm{Ln}^{3+}$ that have larger ionic radius on cationic sites, initially of $9.75 \mathrm{~mol} \%$, was found to have a strong impact on the host crystal structure, promoting the transition from the tetragonal metastable t' phase toward the undesirable cubic phase. This effect could be suppressed by substituting part of the $\mathrm{Y}^{3+}$ with $\mathrm{Ln}^{3+}$ luminescent activators to maintain the overall dopant substitution rate at $9.75 \mathrm{~mol} \%$, which stabilizes the quadratic $\mathrm{t}^{\prime}$ phase with a $\mathrm{c} / \mathrm{a} \sqrt{ } 2$ ratio of 1.01 . Furthermore this partial substitution goes along with a significant increase of the observed luminescence transition intensities, up to 50\% in the case of YSZ:Eu 2 mol\%. $\mathrm{Y}^{3+}$ partial substitution therefore provides an effective solution for optimizing YSZ: Ln phosphors luminescence intensity via non-intrusive composition modifications, especially in the case of $\mathrm{Eu}^{3+}$ for which bright intensity can be achieved at high doping contents. Of all dopants investigated, $\mathrm{Eu}^{3+}, \mathrm{Er}^{3+}$ and $\mathrm{Dy}^{3+}$ exhibit the brightest luminescence in YSZ and present distinct emission peaks in the red, green and blue regions of the visible spectrum respectively that make them compatible for manufacturing multi-wavelength TBC sensors for in-depth sensing. 100-150 thick multilayer TBC architectures integrating three Eu, Er and Dy doped thin layers distributed throughout the thickness were thus successfully deposited on $\mathrm{Ni}(\mathrm{Pt}, \mathrm{Al})$ coated AM1 substrates by dip-coating in a slurry of phosphor powders in sol-gel precursors. Preliminary observations of their microsctructural and luminescence properties confirm the potential of this architecture as a TBC optical sensor for luminescence sensing across the thickness. These results are promising for future investigation of their through-thickness temperature and thermal gradients sensing capabilities with noncontact phosphor thermometry methods.

\section{Acknowledgements}

The authors would like to thank Guillaume Pujol for his kind assistance with the materials synthesis and the deposition of the coatings. Thanks to the École des Mines d'Albi and the Carnot CIRIMAT Institute for their material and financial contribution to this work.

\section{References}

[1] S. Bose, High Temp. Coat, Butterworth-Heinemann, Burlington, 2007, pp. 155-232.

[2] D.S. Rickerby, Design with engineering materials and coatings system for advanced aeroengine applications, Rolls Royce Plc, Derby, UK, 2012.

[3] N.S. Cheruvu, K.S. Chan, R. Viswanathan, Energy Mater. Mater. Sci. Eng. Energy Syst. 1 (2006) 33-47.

[4] H.E. Evans, Surf. Coat. Technol. 206 (2011) 1512-1521.

[5] J.I. Eldridge, T.J. Bencic, S.W. Allison, D.L. Beshears, J. Therm. Spray Technol. 13 (2004) 44-50.

[6] M.M. Gentleman, D.R. Clarke, Surf. Coat. Technol. 188 (2004) 93-100.

[7] M.D. Chambers, D.R. Clarke, Annu. Rev. Mater. Res, Annual Reviews, Palo Alto, 2009, pp. 325-359.

[8] A.L. Heyes, J. Lumin. 129 (2009) 2004-2009.

[9] J.R. Nicholls, R.G. Wellman, R. Steenbakker, J. Feist, Adv. Sci. Technol. 72 (2010) 65-74.

[10] M.M. Gentleman, J.I. Eldridge, D.M. Zhu, K.S. Murphy, D.R. Clarke, Surf. Coat. Technol. 201 (2006) 3937-3941.

[11] J.I. Eldridge, T.J. Bencic, Surf. Coat. Technol. 201 (2006) 3926-3930.

[12] J.I. Eldridge, T.J. Bencic, C.M. Spuckler, J. Singh, D.E. Wolfe, J. Am. Ceram. Soc. 89 (2006) 3246-3251.

[13] L. Pin, F. Ansart, J.-P. Bonino, Y. Le Maoult, V. Vidal, P. Lours, J. Eur. Ceram. Soc. 33 (2013) 269-276

[14] L. Pin, V. Vidal, F. Blas, F. Ansart, S. Duluard, J.-P. Bonino, et al., J. Eur. Ceram. Soc. 34 (2014) 961-974.

[15] L. Pin, C. Pilgrim, J. Feist, Y. Le Maoult, F. Ansart, P. P. Lours, Characterisation of thermal barrier sensor coatings synthesised by sol-gel route, Sens. Actuators Phys. (2014).

[16] K. Amano, H. Takeda, T. Suzuki, M. Tamatani, M. Itoh, Y. Takahashi, Thermal barrier coating, US4774150 (A), 1988.

[17] J.I. Eldridge, J. Singh, D.E. Wolfe, J. Am. Ceram. Soc. 89 (2006) 3252-3254.

[18] C.C. Pilgrim, S. Berthier, J.P. Feist, R.G. Wellman, A.L. Heyes, Surf. Coat. Technol. 209 (2012) 44-51.

[19] S.W. Allison, G.T. Gillies, Rev. Sci. Instrum. 68 (1997) 2615-2650.

[20] J. Bruebach, C. Pflitsch, A. Dreizler, B. Atakan, Prog. Energy Combust. Sci. 39 (2013) 37-60.

[21] J.P. Feist, P.Y. Sollazzo, S. Berthier, B. Charnley, J. Wells, J. Eng. Gas Turbines PowerTrans. Asme 135 (2013).

[22] A.L. Heyes, S. Seefeldt, J.P. Feist, Opt. Laser Technol. 38 (2006) 257-265.

[23] J. Fenech, C. Viazzi, J.-P. Bonino, F. Ansart, A. Barnabé, Ceram. Int. 35 (2009) 3427-3433.

[24] M. Shane, M.L. Mecartney, J. Mater. Sci. 25 (1990) 1537-1544.

[25] A. Lecomte, F. Blanchard, A. Dauger, M.C. Silva, R. Guinebretière, J. Non-Cryst. Solids 225 (1998) 120-124.

26] J. Fenech, Nouvelles compositions de revêtements de zircone substituée (Y, La, Sm, Er) élaborées par la voie sol-gel: applications aux barrières multicouches, Manuscript de thèse Université de Toulouse, 2010.

[27] H.M. Rietveld, J. Appl. Crystallogr. 2 (1969) 65-71

[28] L.B. McCusker, R.B. Von Dreele, D.E. Cox, D. Louër, P. Scardi, J. Appl. Crystallogr. 32 (1999) 36-50.

[29] A.H. Khalid, K. Kontis, H.-Z. Behtash, Proc. Inst. Mech. Eng. Part G J. Aerosp. Eng. 224 (2010) 745-755.

[30] A.H. Khalid, K. Kontis, Luminescence 26 (2011) 640-649.

[31] P.D. Johnson, F.E. Williams, J. Chem. Phys. 18 (2004) 323-326.

[32] P.D. Johnson, F.E. Williams, J. Chem. Phys. 18 (2004) 1477-1483.

[33] L.G.V. Uitert, L.F. Johnson, J. Chem. Phys. 44 (2004) 3514-3522.

[34] L.G.V. Uitert, J. Electrochem. Soc. 107 (1960) 803-806.

[35] D.L. Dexter, J.H. Schulman, J. Chem. Phys. 22 (2004) 1063-1070.

[36] M.M. Gentleman, High temperature sensing of thermal barrier materials by luminescence, ProQuest, 2006.

[37] L. Chen, Y. Liu, Y. Li, J. Alloys Compd. 381 (2004) 266-271.

[38] S. Dhiren Meetei, S. Dorendrajit Singh, N. Shanta Singh, V. Sudarsan, R.S. Ningthoujam, M. Tyagi, et al., J. Lumin. 132 (2012) 537-544.

[39] J. Liao, D. Zhou, B. Yang, R. Liu, Q. Zhang, Opt. Mater. 35 (2012) 274-279.

[40] C. Viazzi, J.-P. Bonino, F. Ansart, A. Barnabé, J. Alloys Compd. 452 (2008) 377-383.

[41] S.A. Tsipas, J. Eur. Ceram. Soc. 30 (2010) 61-72.

[42] J. Fenech, M. Dalbin, A. Barnabe, J.P. Bonino, F. Ansart, Powder Technol. 208 (2011) 480-487.

[43] K. Smits, L. Grigorjeva, D. Millers, A. Sarakovskis, A. Opalinska, J.D. Fidelus, et al., Opt. Mater. 32 (2010) 827-831.

[44] J. Sniezewski, Y. LeMaoult, P. Lours, L. Pin, V.M. Bekale, D. Monceau, et al., Surf. Coat. Technol. 205 (2010) 1256-1261 